\title{
Influence of the Addition of Montmorillonite in an Epoxy Powder Coating Applied on Carbon Steel
}

\author{
Diego Piazza ${ }^{a, b}$, Alessandra Fiorini Baldissera ${ }^{b}$, Sandra Raquel Kunst ${ }^{a}$, Ester Schmidt Rieder ${ }^{c}$, \\ Lisete Cristine Scienza ${ }^{d}$, Carlos Arthur Ferreira ${ }^{d}$, Ademir José Zattera ${ }^{a}$ * \\ ${ }^{a}$ Centro de Ciências Exatas e da Tecnologia, Universidade de Caxias do Sul-UCS, \\ Rua Francisco Getúlio Vargas, 1130, CEP 95070-560, Caxias do Sul, RS, Brazil \\ ${ }^{b}$ Programa de Pós-Graduação em Engenharia de Minas, Metalúrgica e de Materiais - PPGE3M, \\ Universidade Federal do Rio Grande do Sul-UFRGS, Av. Bento Gonçalves, 9500, CEP 91501-970, \\ Porto Alegre, RS, Brazil \\ ${ }^{c}$ Centro de Microscopia Eletrônica e Microanálise, Universidade Luterana do Brasil, \\ Av. Farroupilha, 8001, CEP 92425-900, Canoas, RS, Brazil \\ ${ }^{d}$ Departamento de Materiais, Escola de Engenharia, Universidade Federal do Rio Grande do Sul- \\ UFRGS, Av. Bento Gonçalves, 9500, CEP 91501-970, Porto Alegre, RS, Brazil
}

Received: July 31, 2014; Revised: July 3, 2015

Polymer coatings have been used for the corrosion protection of metal surfaces acting as a physical barrier against several corroding media. In spite of the good efficiency of these coatings their resistance is limited due to the presence of localized defects which give place to localized corrosion. Aiming to improve the barrier properties of these coatings this work has proposed the use of nanocomposites as powder coatings based on a standard formulation of a commercial powder varnish. Nanocomposites with 2 and $4 \mathrm{wt} \%$ contents of organophilic montmorillonite (OMMT) were obtained in the molten state through of a co-rotating twin-screw extruder. The application of the nanocomposite coatings was performed by electrostatic pulverization on mild steel panels. The coatings were characterized to determine their structure using X-ray diffraction (XRD). The morphologies of the coatings were assessed using transmission electron microscopy (TEM). Gloss and adhesion measurements and the flexibility and impact resistance of the coatings were included in the physical assessment of the coatings. The corrosion performance was evaluated by the salt spray test and by electrochemical impedance spectroscopy (EIS). The coatings with clays presented predominantly exfoliated structures, with good dispersion of OMMT in the epoxy matrix. The addition of OMMT reduced the impact resistance, flexibility and gloss but increased the barrier properties of the coatings. The best corrosion performance in $\mathrm{NaCl}$ solution was achieved for $4 \mathrm{wt} \%$ OMMT.

Keywords: corrosion, epoxy resin, montmorillonite, nanocomposite, powder coatings

\section{Introduction}

Recently, because of the improved physical and chemical properties provided by ceramic materials to polymers, lamellar silicate polymer nanocomposites have attracted the attention of both industry and the scientific community ${ }^{1,2}$.

Several polymer matrices have been used in the production of nanocomposites, among which the epoxy resins are highlighted in view of their wide application in engineering ${ }^{3,4}$.

Recently, lamellar silicate nanocomposites have been used as anticorrosion reinforcement in liquid coatings, in special to those based on an epoxy matrix. The improved barrier properties of the coatings are based on the concept of the tortuous path caused by the exfoliation of clay, which reduces the diffusion of gas and/or liquid molecules throughout the coating. Such reduced diffusion highlights the huge potential of the manufacturing of nanocomposites applied to powder coatings via intercalation in the molten state ${ }^{5,6}$.

*e-mail: ajzattera@terra.com.br
Powder coatings are considered to be widely available and environmentally friendly. The significant increase in the growth rate of the use of powder coatings is mainly due to economic factors. Powder coatings have powerful advantages compared to liquid coatings, such as zero solvent emission during and/or after application and essentially no loss of applied material because $98 \%$ of the non-adhered material to the substrate can be reused ${ }^{7,8}$.

A fair anticorrosive performance of a powder coating was observed by Piazza et al. ${ }^{9}$ by incorporating 2 and $4 \mathrm{wt} \%$ of montmorillonite to the formulation of a polyester-based powder coating. They concluded that the coatings barrier properties are directly associated to the clay lamellar structure and to the electrostatic forces existing between matrix and filler, resulting in coatings with better resistance to the permeability of gases and/or liquid molecules.

The corrosion protection is directly related to the improvement in the coatings barrier properties, which are 
influenced by the filler dispersion in the polymer matrix ${ }^{1,6,10-12}$. In this study, organically modified montmorillonite was incorporated in the molten state into an epoxy-based powder coating formulation. To evaluate the influence of the filler addition, the morphology, physical properties, anticorrosive performance and barrier properties of the nanocomposite coatings were characterized.

\section{Experimental Procedures}

\subsection{Materials}

The materials used to obtain the powder coatings included epoxy resin (Araldite GT 7004 ES - Hunstman), curing agent (Casamid 710 Oiled (PR9990) - Thomas Swan \& Co. Ltd.), benzoin (Datiquim Produtos Químicos Ltda), spreading agent (Resiflow ${ }^{\mathrm{TM}}$ PV-60 - Estron Chemical Inc.), and montmorillonite (OMMT)-type Cloisite ${ }^{\circledR}$ 30B (Southern Clay Products).

Carbon steel AISI 1010 substrates were used in the form of $120 \times 70 \times 10 \mathrm{~mm}$ panels.

\subsection{Obtaining and applying nanocomposite epoxy powder coatings}

A commercial formulation of an epoxy-based powder varnish, containing 2 and $4 \mathrm{wt} \%$ OMMT was used. The nanocomposite epoxy powder coating were obtained through incorporation in the melt state in a co-rotating twin-screw extruder, model MH-COR-LAB, L/D 32, thread diameter of $20 \mathrm{~mm}$, manufactured by $\mathrm{MH}$ Equipamentos Ltda. The extruder is equipped with eight heating zones with the load zone at $70^{\circ} \mathrm{C}$, the second zone at $80^{\circ} \mathrm{C}$, and all the other zones at $90^{\circ} \mathrm{C}$. It was employed a speed screw of $400 \mathrm{rpm}$, with feed rate of $5.5 \mathrm{~kg} \cdot \mathrm{h}^{-1}$. After extrusion, the materials were ground in a knife mill bench-top (Cuisinart DCG-20) and sieved (200 mesh) to obtain an average particle size of $40 \mu \mathrm{m}$. The average particle size distribution was measured with a Scirocco 2000M laser granulometer using Mastersizer 2000 software.

To provide improved anchorage for the coating, the carbon steel panels were previously sanded (sandpaper \#320, \#400 and \#600), degreased and submitted to a pretreatment zinc-based phosphatizing. The coatings were applied on the substrates with an electrostatic spray gun (type corona, TCA ECO Tecnoavance, model 301). Curing of the coatings was performed in an air circulation oven at $200^{\circ} \mathrm{C}$ for $10 \mathrm{~min}$.

The powder coatings were identified according to the percentage of OMMT used, for example, EPC/2-30B $(\mathrm{EPC}=$ epoxy-based powder coating) and 2-30B ( $2 \mathrm{wt} \%$ of Cloisite $30 \mathrm{~B}$ OMMT).

\subsection{Characterization}

After curing the nanocomposite coatings were characterized to determine their structure and morphology by X-ray diffraction (XRD) in a Shimadzu - XRD 6000 diffractometer using $\mathrm{Cu}-\mathrm{K} \alpha$ radiation, a voltage of $40 \mathrm{kV}$, a current of $30 \mathrm{~mA}$, scanning at $2 \theta$ from $1^{\circ}$ to $12^{\circ}$ with a fixed scanning time with steps of $0.005^{\circ} / 5 \mathrm{~s}$ and transmission electron microscopy (TEM) using a Philips EM 208 S microscope operating at an acceleration voltage of $100 \mathrm{kV}$. For TEM sections of $100 \mathrm{~nm}$ thickness were prepared using a Leica Ultracut UcT ultramicrotome at $23 \pm 2{ }^{\circ} \mathrm{C}$.

The medium thickness of the coatings $(40.5 \pm 0.7 \mu \mathrm{m})$ was determined by magnetic method according to ASTM D7378 ${ }^{13}$ using an Elcometer ${ }^{\circledR} 345$ gauge. The gloss measurement was performed using a Zehntener Gloss $60^{\circ}$ glossmeter model ZGM 1020, with calibration for an angle of $60^{\circ}$ in 92 gloss units according to ASTM D523 ${ }^{14}$. The adhesion to the substrate was measured following Method B of ASTM D3359 ${ }^{15}$. The flexibility test was done according to ASTM D522 ${ }^{16}$ Method using the Gardner Conical Mandrel instrument from BYK Gardner. The impact resistance measurements were performed using a Heavy-Duty Impact Tester of BYK Gardner at an impact force of $1 \mathrm{~kg} \times 500 \mathrm{~mm}$.

The corrosion performance of the coatings applied to the metal substrate was evaluated by two methods. The coatings were exposed to salt spray according to ASTM B117 $7^{17}$ for a period of $504 \mathrm{~h}$ in a Bass Equipamentos chamber model USX-6000/9000. The coatings were also characterized by electrochemical impedance spectroscopy (EIS) using a potentiostat/galvanostat ECOCHEMIE BV - Autolab PGSTAT 302 assisted by FRA software. The impedance data were measured periodically at an open circuit potential in $3.5 \mathrm{wt} \% \mathrm{NaCl}$ solution, in the frequency range of $10^{6}$ to $1 \mathrm{~Hz}$ and at an amplitude of sinusoidal perturbation of $10 \mathrm{mV} \mathrm{AC}$.

\section{Results and Discussion}

The data provided by the X-ray diffraction analysis performed on the cured epoxy resin-based powder coatings are shown in the diffractograms of Figure 1. The spectra exhibit two distinct peaks of different intensities associated with the " $\mathrm{d}_{001}$ " basal spacing.

The diffractograms exhibit a peak shift for OMMT $\left(2 \theta=4.8^{\circ}\right)$ at angles lower than $2.25^{\circ}$, indicating an increased " $\mathrm{d}_{001}$ " basal spacing from $1.84 \mathrm{~mm}$ to values higher than $3.93 \mathrm{~nm}$, as calculated on the basis of the Bragg law $(n \lambda=2 d \sin \theta)$. The values for the " $\mathrm{d}_{001}$ " basal spacing are listed in Table 1 .

The expansion of the " $\mathrm{d}_{001}$ " basal spacing caused by the high degree of intercalation of the epoxy resin within the montmorillonite galleries indicates the higher dispersion of

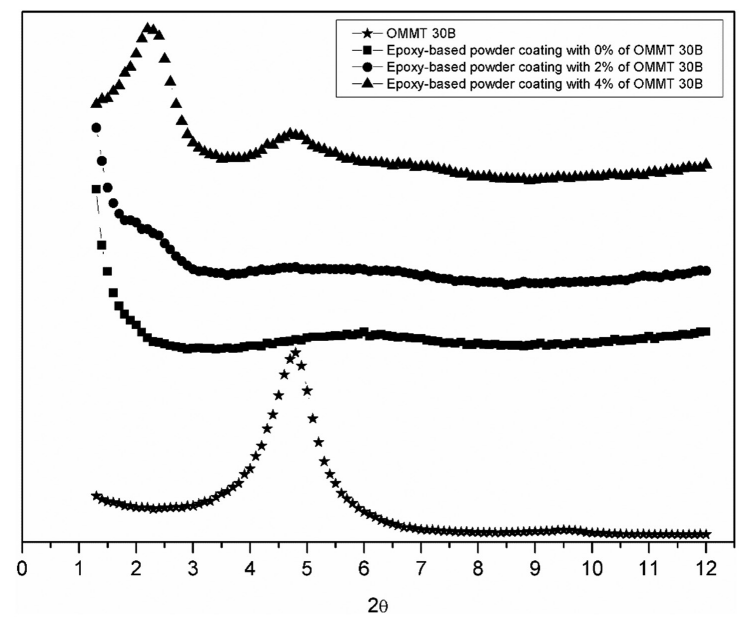

Figure 1. Superposition of the X-ray diffractograms of OMMT and epoxy-based powder coatings with different OMMT contents. 
the clay in the polymer matrix, thus providing evidence of the presence of nanocomposites of predominantly exfoliated phase $^{1,4,9,10,18-21}$

The high intercalation of the epoxy resin towards the interior of the OMMT galleries of the cured samples is more relevant for the EPC/2-30B sample, with a shift of the " $\mathrm{d}_{001}$ " basal plane towards values higher than $5.25 \mathrm{~nm}$ (Table 1), which results in a nanocomposite with an exfoliated structure. It is probably associated with the lower clay concentration and the high shear during the manufacturing process ${ }^{18,21}$.

Transmission electron microscopy was used to characterize the dispersion of the filler particles in the polymer matrix and the morphological structure of the cured samples. In the micrographs of Figure 2, there are light regions related to the epoxy matrix and dark regions associated to the montmorillonite particles. The images indicate high dispersion of the clays in the polymer matrix.

Nanocomposites of predominantly exfoliated phase with intercalation of epoxy resin within the OMMT galleries are observed in Figure 2, similarly to the observed in the literature ${ }^{22}$. This structure is more evident for the sample with $2 \mathrm{wt} \%$ of OMMT, corroborating the XRD data (Figure 1). Similar results were observed by Piazza et al. ${ }^{\circ}$ by incorporating OMMT 30B into a polyester resin-based powder coating.

As also observed in the literature ${ }^{4}$, the increase in OMMT concentration in the powder coating formulation caused a reduction in gloss, measured in gloss units (G. U.) and listed in Table 2. The gloss index values for the coatings OMMT-free and with $2 \mathrm{wt} \%$ OMMT were above the industrial standard required for high gloss varnishes (100 G.U.). The gloss index of the sample with $4 \mathrm{wt} \%$ OMMT was 57.9 G.U., ranking this sample as a semi-gloss varnish according to industrial standards because this gloss value is in the range from 50 to 80 G.U. The gloss reduction can be associated to surface irregularities caused by the higher amount of clay at the coating surface ${ }^{4}$.

The results for the adhesion test of all samples did not exhibit any removed areas ( $0 \%$ removing), thus achieving classification 5B in accordance with ASTM D3359-Method B ${ }^{15}$. These results provide evidence of high mechanical resistance coatings regarding adhesion, which is an important factor in terms of the anticorrosive properties of the coatings. As stated by García et al..$^{23}$, the satisfactory adhesion properties can be associated with the use of appropriate curing temperature and use of high quality primers. The data show that the addition of clay did not reduce the adhesion of the coating to the substrate. Similar results were obtained by Bagherzadeh \& Mahdavi ${ }^{18}$ and by Nematollahi et al. ${ }^{24}$, who studied the addition from 1 to $5 \mathrm{wt} \%$ of montmorillonite clay in formulations of epoxy resin-based liquid coatings.

The data for the conical mandrel flexibility test of the organic epoxy resin-based powder coatings exhibit good performance for the coating OMMT-free and with $2 \mathrm{wt} \%$ OMMT. However, the coating with $4 \mathrm{wt} \%$ OMMT coating exhibited cracks in the bending region, as shown in Figure 3.

The aspect of the coated metal substrates after tests of rapid deformation (impact resistance tests) is shown in Figure 4. Based on visual analysis (Figure 4a) the coating OMMT-free was found to have excellent resistance to rapid deformation. The EPC/2-30B and EPC/4-30B samples had reduced impact resistance as can be seen by cracks and displaced coatings observed in Figure $4 \mathrm{~b}$ and $4 \mathrm{c}$.

Table 1. Values for the " $\mathrm{d}_{001}$ " basal spacing calculated by the Bragg law for OMMT and for the epoxy resin-based powder coatings with the addition of OMMT.

\begin{tabular}{ccc}
\hline Sample & $\left.\mathbf{2 \theta} \mathbf{(}^{\mathbf{0}}\right)$ & $\mathbf{d}_{\mathbf{0 0 1}}(\mathbf{n m})$ \\
\hline OMMT 30B & 4.8 & 1.84 \\
EPC/2-30B (film) & $<1.65$ & $>5.35$ \\
EPC/4-30B (film) & 2.25 & 3.93 \\
\hline
\end{tabular}

Table 2. Gloss measurement of the epoxy resin-based powder coatings applied on carbon steel substrates.

\begin{tabular}{cc}
\hline Sample & Gloss Units (G.U.) \\
\hline EPC/0 & 107.3 \\
EPC/2-30B & 105.4 \\
EPC/4-30B & 57.9 \\
\hline
\end{tabular}

(a)
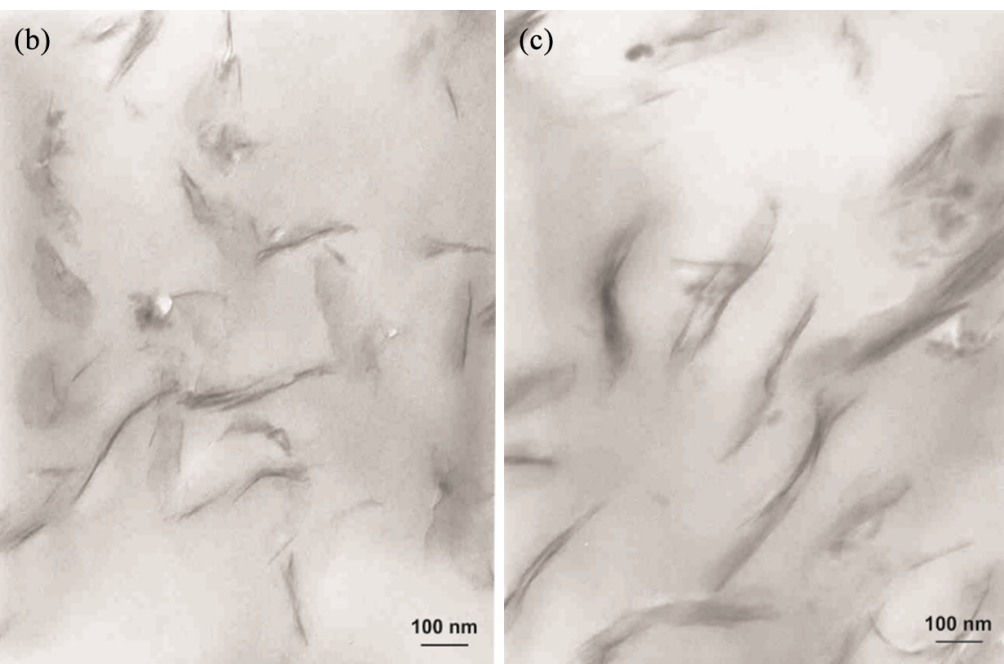

Figure 2. TEM micrographs of the cured epoxy resin-based powder coatings (a) EPC/0, (b) EPC/2-30B and (c) EPC/4-30B. 

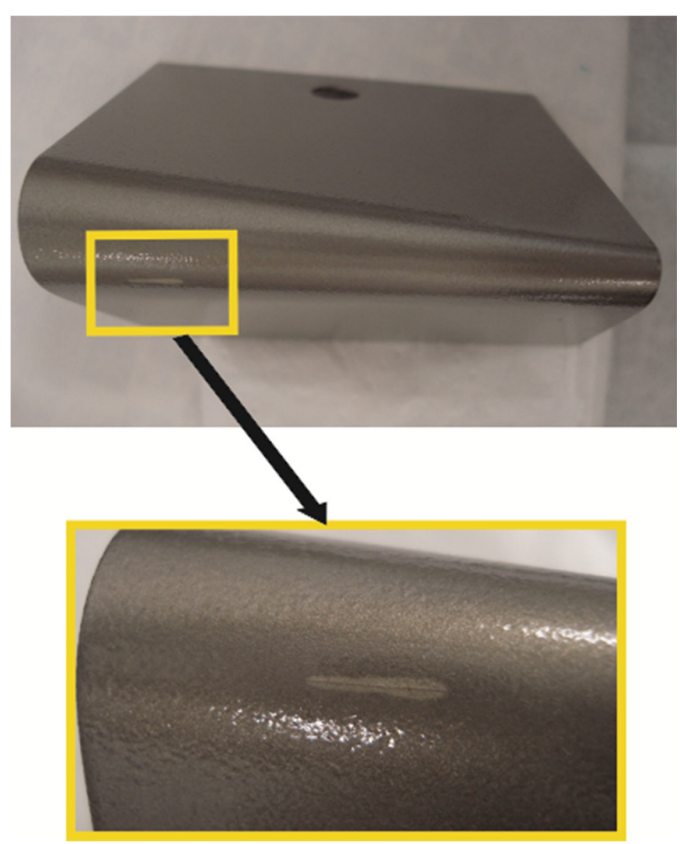

Figure 3. Aspect of the result of the conical mandrel flexibility test for EPC/4-30B applied on carbon steel.

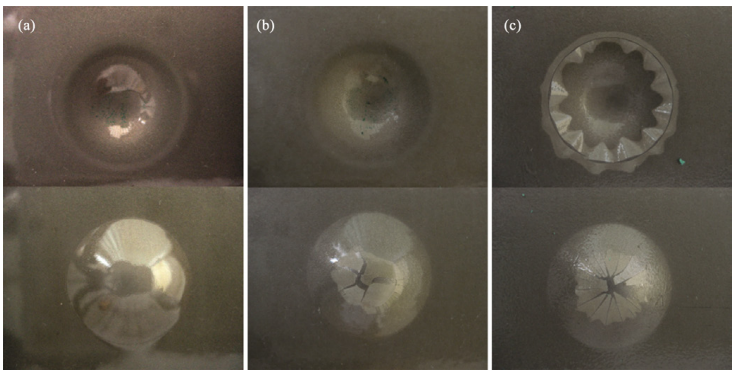

Figure 4. Aspect of the samples after the impact resistance test of the epoxy resin-based powder coatings applied to carbon steel: (a) EPC/0, (b) EPC/2-30B and (c) EPC/4-30B.
Similar to the results observed for the flexibility test, the lower resistance of these samples to rapid deformation may be associated with the increased stiffness of the material caused by the presence of ceramics, which may give rise to the formation of sites prone to initiation and propagation of cracks.

The increase in the OMMT content in the formulation of the coatings imparts more stiffness to the films, which may be associated with the high aspect ratio of the clay nanoparticles and the reduction in the molecular mobility caused by the restrictions imposed by the intercalation of the epoxy resin molecules within the OMMT galleries. The fragility of the coatings can still be associated with the typical stiffness of the predominantly exfoliated structure of the nanocomposites ${ }^{22}$, as observed in XRD and TEM analysis. Thus, the addition of $4 \mathrm{wt} \%$ OMMT in the formulation of the epoxy resin-based powder coatings is critical to the flexibility and impact resistance properties of the film.

The salt spray test assessed the performance of the corrosion protection of the epoxy resin-based powder coating with and without the addition of OMMT. Figure 5 shows the aspect of the samples after exposure to salt spray for 504 hours indicating the presence of corrosion products near the incision. No bubbles or corrosion spots in the surface was observed.

The increase in corrosion resistance is associated with the nature, shape and size of the filler. Piazza et al. ${ }^{9}$ reported an increased barrier effect with the addition of montmorillonite to a polyester-based powder coating. This effect was attributed to the increase of the difficulty of diffusion (tortuosity) of liquids or gases molecules throughout the polymer film due to the predominantly exfoliated structure of the nanocomposite.

EIS analysis revealed improved barrier properties for the coating containing OMMT, which exhibited behavior similar to an ideal capacitor. This behavior is evidenced by the formation of nearly straight lines near the $Z_{\text {imag. }}$ (Z') axis ${ }^{22}$ as observed in the Nyquist plots illustrated in Figure 6. This behavior is associated to the presence of lamellar silicates dispersed in the polymer matrix, which form barriers along the film
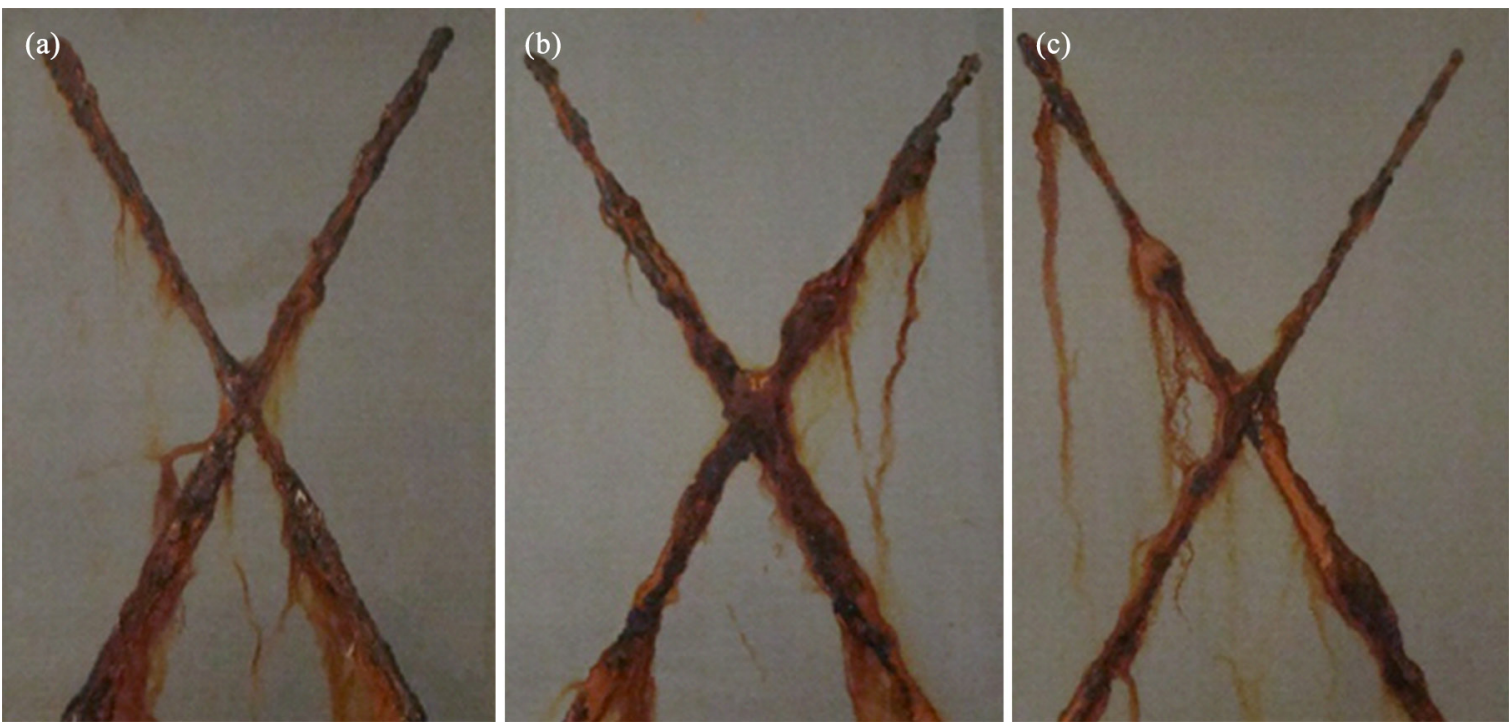

Figure 5. Aspect of the incision region of coated steel after $504 \mathrm{~h}$ of exposure to salt spray: (a) EPC/0, (b) EPC/2-30B and (c) EPC/4-30B. 


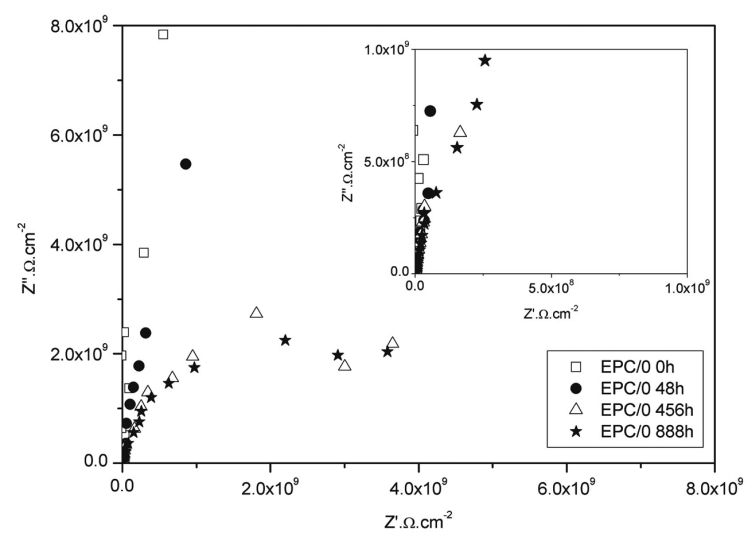

(a)

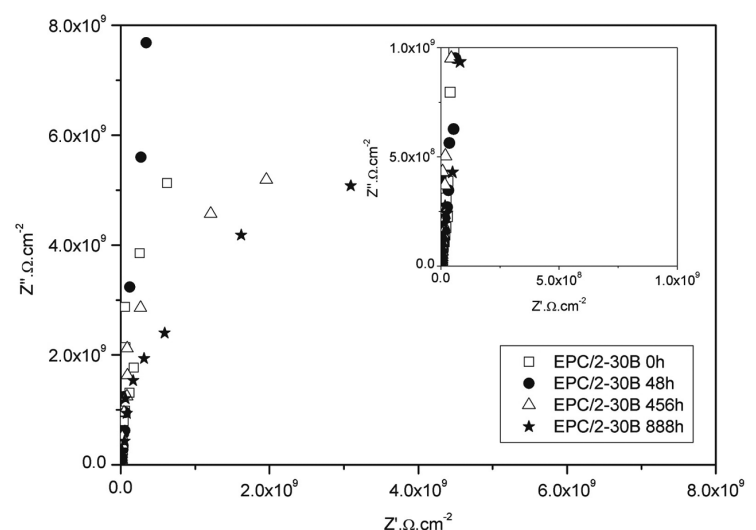

(b)

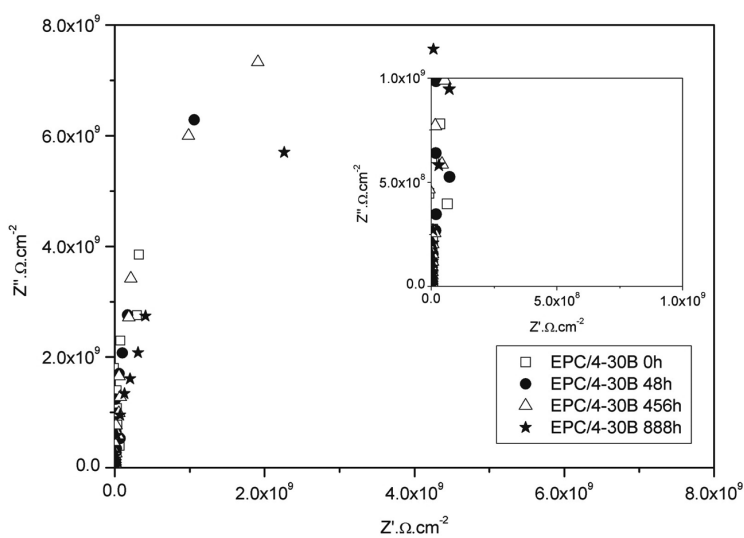

(c)

Figure 6. Nyquist plots of coated steel (a) EPC/0, (b) EPC/2-30B and (c) EPC/4-30B, after different immersion times (0 h, 48 h, 456 h and $888 \mathrm{~h}$ ) in $3.5 \mathrm{wt} \% \mathrm{NaCl}$.

thickness increasing its tortuosity of the diffusion channels and hindering the passage of gases and liquids molecules ${ }^{25}$.

The coating OMMT-free (Figure 6a) showed greater decrease of the coating resistance with the immersion time in relation to the coatings with OMMT. The loss in the corrosion protection of a coating can be followed by the trend to form the capacitive arc characterized by the coating charge reduction caused by the beginning of the corrosive process, which results from diffusion of water and $\mathrm{Cl}^{-}$ions throughout the coating and reaching the metal surface ${ }^{25}$. As shown in Figure $6 \mathrm{~b}$ and $\mathrm{c}$, the $4 \mathrm{wt} \%$ OMMT coating exhibits better barrier properties than $2 \mathrm{wt} \%$ OMMT. This behavior indicates that an increasing of clay concentration improves the barrier properties, which may be associated to the good nanofiller dispersion in the polymer matrix, as observed in TEM micrographs.

A more detailed interpretation of the EIS measurements was performed by fitting the experimental plots (Figure 7 and 8 ) using equivalent electrical circuit models in order to simulate the electrochemical behavior of the studied coatings. The equivalent electrical circuit that provided the best fitting to the data obtained from Bode plots (Figure 7 and 8 ) was the $\mathrm{R}(\mathrm{RC})$ circuit (Figure 9), where $\mathrm{R} 1$ is the solution resistance, $\mathrm{R} 2$ is the coating resistance, and $\mathrm{C}$ is the coating capacitance. These results agree with those reported in the literature ${ }^{26}$.

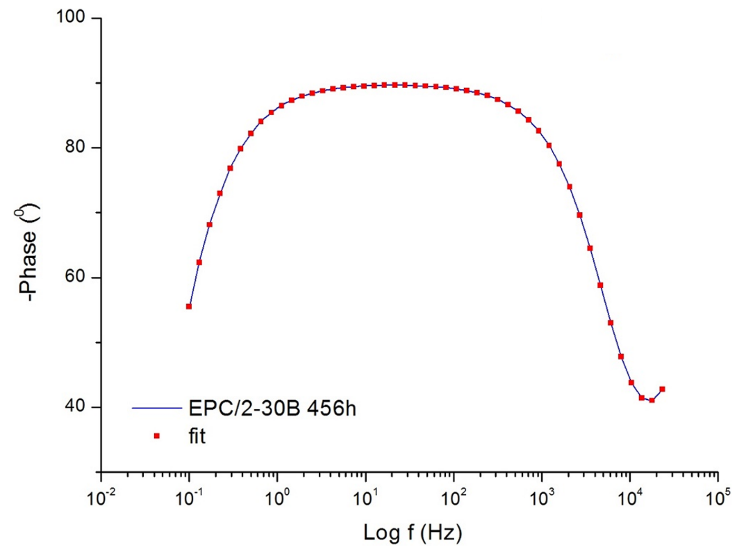

Figure 7. Bode plots of the epoxy resin-based powder coatings of EPC/2-30B applied to carbon steel substrates after $456 \mathrm{~h}$ in $3.5 \mathrm{wt} \% \mathrm{NaCl}$.

Electrical circuit models were used to fit impedance curves, Table 3 show electrical element values obtained by fitting for a epoxy resin-based powder coatings films up to $456 \mathrm{~h}$ of immersion in $\mathrm{NaCl}$ solution. These results are related to the interaction of the electrolyte with the film, such as its permeation through of the film, which is not an instantaneous process. In this system is observed a phenomenon at high 


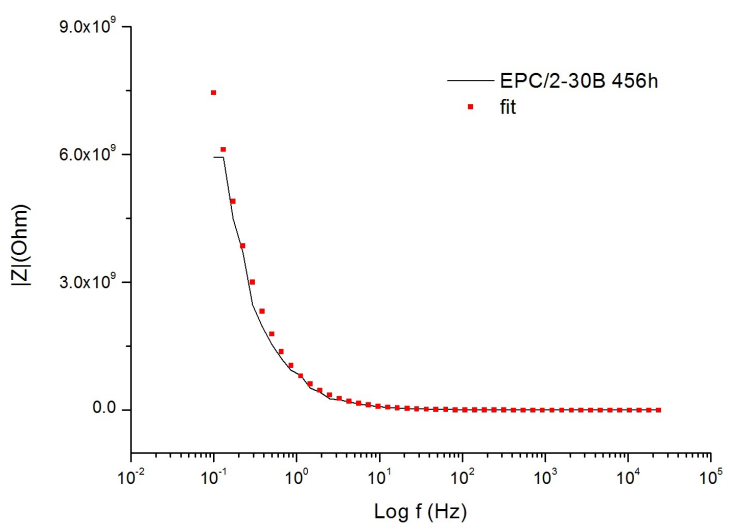

Figure 8. Impedance modulus Bode plots of EPC/2-30B applied to carbon steel after $456 \mathrm{~h}$ in $3.5 \mathrm{wt} \% \mathrm{NaCl}$.

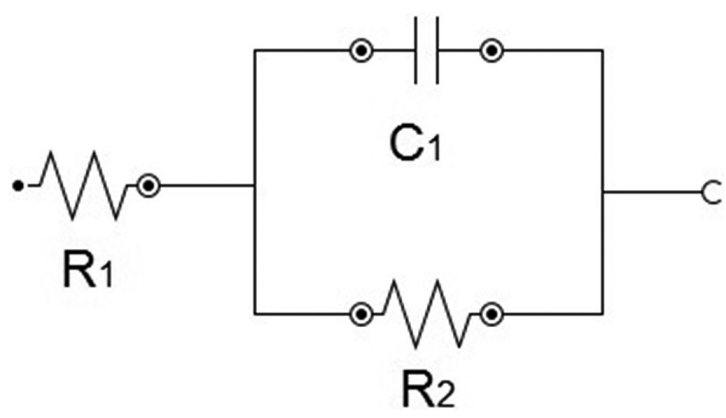

Figure 9. Equivalent electrical circuit of the Nyquist plots for the epoxy resin-based powder coatings.

\section{References}

1. Carrasco $F$ and Pagès $P$. Thermal degradation and stability of epoxy nanocomposites: Influence of montmorillonite content and cure temperature. Polymer Degradation \& Stability. 2008; 93(5):1000-1007. http://dx.doi.org/10.1016/j. polymdegradstab.2008.01.018.

2. Bertuoli PT, Piazza D, Scienza LC and Zattera AJ. Preparation and characterization of montmorillonite modified with 3-aminopropyltriethoxysilane. Applied Clay Science. 2014; 87:46-51. http://dx.doi.org/10.1016/j.clay.2013.11.020.

3. Singh-Beemat J and Iroh JO. Iroh. Characterization of corrosion resistant clay/epoxy ester composite coatings and thin films. Progress in Organic Coatings. 2012; 74(1):173-180. http:// dx.doi.org/10.1016/j.porgcoat.2011.12.006.

4. Piazza D, Lorandi NP, Pasqual CI, Scienza LC and Zattera AJ. Influence of a microcomposite and a nanocomposite on the properties of an epoxy-based powder coating. Materials Science and Engineering A. 2011; 528(22-23):6769-6775. http://dx.doi.org/10.1016/j.msea.2011.05.062.

5. Baldissera AF, Freitas DB and Ferreira CA. Electrochemical impedance spectroscopy investigation of chlorinated rubberbased coatings containing polyaniline as anticorrosion agent. Materials and Corrosion. 2010; 61(9):790-801. http://dx.doi. org/10.1002/maco.200905254.

6. Sun L, Boo W-J, Clearfield A, Sue H-J and Pham HQ. Barrier properties of model epoxy nanocomposites. Journal of Membrane Science. 2008; 318(1-2):129-136. http://dx.doi.org/10.1016/j. memsci.2008.02.041.
Table 3. Electrical elements fitted values and their associated error after $456 \mathrm{~h}$ of immersion in $\mathrm{NaCl}$ solution.

\begin{tabular}{lcc}
\hline & Fitted circuit & Error (\%) \\
\hline $\mathrm{R} 1$ & $50.4 \Omega$ & $2.06 \%$ \\
$\mathrm{R} 2$ & $1.28 \times 10^{10} \Omega$ & $3.42 \%$ \\
$\mathrm{C} 1$ & $1.70 \times 10^{-10} \mathrm{~F}$ & $6.18 \%$ \\
\hline
\end{tabular}

frequencies associated with the formation of an effective barrier between the metal and the electrolyte. The percentage fitting error shown in Table 3 is relatively low $(<6.2 \%)$.

\section{Conclusions}

X-ray diffraction and transmission electron microscopy analyses indicated predominantly exfoliated structures for the organic coatings, with good dispersion of OMMT in the epoxy matrix.

The incorporation of OMMT into the polymer coatings reduced the impact resistance, flexibility and gloss in relation to the coating OMMT-free.

The corrosion protection performance was satisfactory for all coatings submitted to the salt spray exposure. The improved barrier properties provided by the OMMT were evidenced by EIS analysis and the coating with $4 \mathrm{wt} \%$ OMMT showed the best corrosion performance.

\section{Acknowledgements}

The authors are indebted to UCS, UFRGS, ULBRA, CNPq, CAPES and Fapergs for their financial support of this research and to Pulverit do Brasil Company by resin supply.

7. Huang Q, Zhang $\mathrm{H}$ and Zhu J. Flow properties of fine powders in powder coating. Particuology. 2010; 8(1):19-27. http://dx.doi. org/10.1016/j.partic.2009.05.007.

8. Koleske JV. Paint and coating testing manual: 15th edition of the Gardner-Sward handbook. Bridgeport: ASTM Stock Number; 2012. p. 957-961.

9. Piazza D, Silveira DS, Lorandi NP, Birriel EJ, Scienza LC and Zattera AJ. Polyester-based powder coatings with montmorillonite nanoparticles applied on carbon steel. Progress in Organic Coatings. 2012; 73(1):42-46. http://dx.doi.org/10.1016/j. porgcoat.2011.08.018.

10. Thi Xuan Hang T, Truc TA, Nam TH, Oanh VK, Jorcin J-B and Pébère N. Corrosion protection of carbon steel by an epoxy resin containing organically modified clay. Surface and Coatings Technology. 2007; 201(16-17):7408-7415. http:// dx.doi.org/10.1016/j.surfcoat.2007.02.009.

11. Paul DR and Robeson LM. Polymer nanotechnology: nanocomposites. Polymer. 2008; 46:3187-3204.

12. Zainuddin S, Hosur MV, Zhou Y, Kumar A and Jeelani S. Durability studies of montmorillonite clay filled epoxy composites under different environmental conditions. Materials Science and Engineering A. 2009; 507(1-2):117-123. http://dx.doi. org/10.1016/j.msea.2008.11.058.

13. American Society for Testing and Materials - ASTM. ASTM D7378: standard practice for measurement of thickness of applied coating powders to predict cured thickness. West Conshohocken; 2010. 
14. American Society for Testing and Materials-ASTM. ASTM D523: standard test method for specular gloss. West Conshohocken; 2008.

15. American Society for Testing and Materials - ASTM. ASTM D3359: standard test methods for measuring adhesion by tape test. West Conshohocken; 2009.

16. American Society for Testing and Materials - ASTM. ASTM D522/D522M: standard test methods for mandrel bend test of attached organic coatings. West Conshohocken; 2013.

17. American Society for Testing and Materials - ASTM. ASTM B117: standard practice for operating salt spray (fog) apparatus. West Conshohocken; 2011.

18. Bagherzadeh MR and Mahdavi F. Preparation of epoxy-clay nanocomposite an investigation on its anti-corrosive behavior in epoxy coating. Progress in Organic Coatings. 2008; 60:106109.

19. Azeez AA, Rhee KY, Park SJ and Hui D. Epoxy clay nanocomposites: processing, properties and applications: A review. Composites. Part B, Engineering. 2012; 45(1):308-320. http://dx.doi.org/10.1016/j.compositesb.2012.04.012.

20. Paiva LB, Morales AR and Valenzuela Díaz FR. Organoclays: properties, preparation and applications. Applied Clay Science. 2008; 42(1-2):8-24. http://dx.doi.org/10.1016/j.clay.2008.02.006.

21. Ceccia S, Turcato EA, Maffettone PL and Bongiovanni R. Nanocomposite UV-cured coatings: Organoclay intercalation by an epoxy resin. Progress in Organic Coatings. 2008; 63(1):110115. http://dx.doi.org/10.1016/j.porgcoat.2008.04.012.

22. Akbari B and Bagheri R. Deformation mechanism of epoxy/clay nanocomposite. European Polymer Journal. 2007; 43(3):782788. http://dx.doi.org/10.1016/j.eurpolymj.2006.11.028.

23. García SJ, Serra A and Suay J. New powder coatings with low curing temperature and enhanced mechanical properties obtained from DGEBA epoxy resins and meldrum acid using erbium triflate as curing agent. Journal of Polymer Science. Part A, Polymer Chemistry. 2007; 45(11):2316-2327. http:// dx.doi.org/10.1002/pola.21998.

24. Nematollahi M, Heidarian M, Peikari M, Kassiriha SM, Arianpouya N and Esmaeilpour M. Comparison between the effect of nanoglass flake and montmorillonite organoclay on corrosion performance of epoxy coating. Corrosion Science. 2010; 52:1808-1817

25. Shi X, Nguyen TA, Suo Z, Liu Y and Avci R. Effect of nanoparticles on the anticorrosion and mechanical properties of epoxy coating. Surfce \& Coating Technolology. 2009; 204(3):237-245. http:// dx.doi.org/10.1016/j.surfcoat.2009.06.048.

26. Suegama PH, Fugivara CS, Benedetti AV, Delgado J and Guilemany JM. Electrochemical characterisation study of coatings obtained by High Velocity Oxy-Fuel Sprayin (HVOF). Portugaliae Electrochimica Acta. 2003; 21(2):141-154. http:// dx.doi.org/10.4152/pea.200302141. 